\title{
Comparison of continuous positive airway pressure and non-invasive positive pressure ventilation as modes of non-invasive respiratory support for neonates in a Level III neonatal intensive care unit
}

\author{
*Anne Kaushalya Gomez ${ }^{1}$, Medha Weerasekara ${ }^{2}$, Prasad Wickramaarachchi², Kanthi \\ Prathapasinghe $^{2}$, Ayani Wickramanayaka ${ }^{2}$
}

Sri Lanka Journal of Child Health, 2018; 47: 242-248

\begin{abstract}
Objectives: To compare the effectiveness of continuous positive airway pressure (CPAP) and non-invasive positive pressure ventilation (NIPPV) in neonates with mild to moderate respiratory distress.
\end{abstract}

Method: A single centre randomized controlled trial was conducted at the Sri Jayawardenepura General Hospital, Sri Lanka from January to December 2015. The trial was registered with The Clinical Trials Registry 'Clinical Trials.gov' retrospectively. Eighty neonates admitted to the neonatal intensive care unit (NICU) were randomly allocated to NIPPV and CPAP. Outcomes of respiratory support were observed and information on risk factors were obtained by going through the bed head tickets of the study cohort. Data analysis was done using SPSS 20 software.

Results: Infants treated with NIPPV and CPAP had comparable demographic data and clinical status at the time of enrolment into the study. Infants treated initially with NIPPV needed less endotracheal ventilation than infants treated with CPAP $(35 \%$ vs $40 \%, p=0.644)$ but this difference is not statistically significant.

Conclusions: The risks for respiratory failure and the need for ventilation were not statistically significantly different whether using NIPPV or CPAP.

1Teaching Hospital Mahamodara, Galle, Sri
Lanka, ${ }^{2}$ Sri Jayawardenepura Teaching
Hospital, Sri Lanka
${ }^{*}$ Correspondence: kaushalya.gomez@yahoo.com

(Received on 20 November 2017: Accepted after revision on 22 December 2017)

The authors declare that there are no conflicts of interest

Personal funding was used for the project.

Open Access Article published under the Creative

Commons Attribution CC-BY (c) (P)
DOI: http://dx.doi.org/10.4038/sljch.v47i3.8547

(Key words: Respiratory distress, non-invasive positive pressure ventilation, continuous positive airway pressure)

\section{Introduction}

Respiratory distress accounts for $30-40 \%$ of admissions to neonatal intensive care units (NICUs) and special care baby units (SCBUs) ${ }^{1}$. Whilst non-invasive respiratory support causes minimal damage to the developing neonatal lung parenchyma and minimal systemic damage, invasive ventilation can lead to permanent lung damage with poor respiratory capacity, frequent wheezing and broncho-pulmonary dysplasia. Invasive ventilation also predisposes the neonate to ventilator associated pneumonia, bacterial and fungal sepsis, prolonged NICU stay, over-crowding and is an economic burden to the parents and state ${ }^{2,3}$.

National Emergency Obstetric and Neonatal Care Needs Assessment Country Report published in 2012 by the Ministry of Health and the Family Health Bureau of Sri Lanka shows total ventilation as a percentage of total admissions to neonatal care units to be $5.4 \%$ and nasal CPAP support as $3.9 \%$. There is no data regarding NIPPV use. Most centres in Sri Lanka use CPAP as a non-invasive method and conventional ventilation as an invasive method.

NIPPV is the augmentation of CPAP with superimposed inflations to a set peak pressure. Mechanism of action of NIPPV remains uncertain. Hypotheses include increasing pharyngeal dilation, improving respiratory drive, increasing mean airway pressure, allowing recruitment of alveoli, increasing functional residual capacity and increasing tidal and minute volume ${ }^{4,5,6}$. Previous studies on comparison between CPAP and NIPPV on weaning from invasive ventilation showed, weaning to NIPPV leads to better outcome ${ }^{4,7-10}$. A recent synchronised NIPPV study demonstrated a relative risk reduction for intubation in the first 72 hours in the NIPPV 
group compared to CPAP (RR $0.60,95 \%$ CI $0.43,0.83)^{11}$. There is some evidence to suggest that NIPPV may be useful as a mode of primary respiratory support, but the evidence is not conclusive ${ }^{12}$. However, in Sri Lanka, such studies have not been done.

\section{Objectives}

- To compare the effectiveness of CPAP and NIPPV in neonates with mild to moderate respiratory distress.

- To describe neonatal factors associated with CPAP and NIPPV support.

- To compare the length of hospital stay in neonates who received CPAP and NIPPV

- To compare the time taken to achieve full enteral nutrition in neonates who received CPAP and NIPPV.

\section{Method}

Study design: Randomized controlled trial. The trial was registered with The Clinical Trials Registry 'Clinical Trials.gov' retrospectively and the reference number is NCT03347136.

Study setting: Study was carried out in the NICU of the Sri Jayawardenepura General Hospital (SJGH) from January to December 2015. There are 06 infant ventilators in NICU of SJGH (3 SLE 2000 and 3 Bear CUB 750 PSV). Respiratory support (conventional ventilation, CPAP and NIPPV) was given through these ventilators. The neonatal soft tip curved nasal cannula with tubing was used for non-invasive respiratory support. The nasal cannula is connected to the ventilator via an endotracheal tube connector. Systems were regularly monitored. Cannula size was chosen to comfortably fit the infant's nostrils. CPAP was started with PEEP 05 and increased up to PEEP 09 according to severity of baby's condition $^{13}$. NIPPV was started with IMV rate 30, PIP 20 and PEEP 5. Settings were increased according to the severity of baby's condition ${ }^{13}$.

Inclusion criteria: All neonates with mild to moderate respiratory distress, requiring non-invasive respiratory support on admission as defined by one or more of the following ${ }^{8,13,14}$ :

- Respiratory distress needing 3 litres of oxygen to maintain saturation more than $90 \%$

- Silverman Anderson score of 4-6

- Apnoea

a. More than 2 apnoeic attacks needing tactile stimulation for recovery b. One apnoeic attack needing resuscitation

\section{Exclusion criteria:}

- Major congenital anomalies

- Presence of cardiovascular instability [sepsis, anaemia or severe intraventricular haemorrhage (IVH)].

- Intubation needed on admission to the NICU

- Major cardiac disease excluding patent ductus arteriosus (PDA)

Sample size: Sample size calculation was done based on the percentage needing ventilation in the comparison study of Kugelman A et al..$^{15}$. Significance level was taken as $5 \%$. Power of study was taken as $80 \%$. Ratio of subjects of the two arms needing intubation was 1: 2 . Percentage needing ventilation in CPAP arm was $31 \%$ and in NIPPV arm was $62 \%$. Applying these numbers to the sample size calculation formula gives need for 40 neonates in each arm with a total sample size of 80 .

Sampling method: All neonates fulfilling inclusion and exclusion criteria were registered in the study and a serial number issued. They were allocated to the two arms of the study randomly based on a previously generated random allocation schedule.

Data collection: All the medical officers as well as the nursing staff were educated with practical demonstrations on how to assess babies with respiratory distress and how to carry out a Silverman Anderson Score.

The neonates who were included in the study were monitored and managed according to the SJGH NICU management protocol.

After initiation of non-invasive ventilation the outcome was measured in the following ways:

- Failure of non-invasive respiratory support by requirement for endotracheal ventilation within 72 hours of starting treatment.

- Time to stop oxygen support (on room air without respiratory distress or apnoea)

- Incidence of grade III/IV IVH

- Time taken to achieve full enteral feeds.

- Length of hospital stay.

Neonates with failure of non-invasive ventilation were given invasive respiratory support. The criterion for failure of 
non-invasive support was considered as one of the following ${ }^{2,3,13}$ :

- Clinical deterioration (Worsening tachypnoea, persistent grunting, gasping, respiratory exhaustion)

- $\quad$ Silverman score $\geq 7$

- $\quad$ Blood gases: $\mathrm{pH} \leq 7.25, \mathrm{pCO} 2 \geq 50$ $\mathrm{mmHg}, \mathrm{PaO} 2 \leq 50 \mathrm{~mm} \mathrm{Hg}$

- Arterial oxygen saturation by pulse-oximetry $(\mathrm{SpO} 2)<90 \%$ while on $\mathrm{FiO} 255 \%$

- $\quad$ Apnoea ( $>2$ apnoeic attacks needing tactile stimulation for recovery or one apnoeic attack needing resuscitation)

Ethical aspects: Ethical approval was obtained from the Ethical Review Committee of SJGH, Kotte. Written informed consent was obtained from parents or guardians of eligible infants before randomization. The data sheets did not contain names and were anonymous. Data was stored under lock and key with restricted access only to the principal investigators. The computerized data were password protected and were only available to the investigators.

Statistical analysis: All data were collected into an Excel database and analysed using SPSS 20 software. Relative risk was calculated for main outcome and Chi square significance was assessed for association with risk factors. $\mathrm{P}$ value less than 0.05 was considered statistically significant.

\section{Results}

Total sample of 80 newborns was randomly equally allocated into two treatment categories; NIPPV $(n=40)$ and CPAP $(n=40)$. As shown in Table 1, the distribution of the demographic and birth variables in the 2 groups did not demonstrate statistically significant differences.

Table 1: Demographic data of the neonates included in the study

\begin{tabular}{|c|c|c|c|c|}
\hline Variable & $\begin{array}{c}\operatorname{NIPPV}(n=40) \\
\text { No. }(\%) \\
\end{array}$ & $\begin{array}{c}\text { CPAP }(n=40) \\
\text { No. }(\%) \\
\end{array}$ & $\begin{array}{c}\text { Total }(n=80) \\
\text { No. }(\%) \\
\end{array}$ & $\begin{array}{c}\text { Level of } \\
\text { significance }\end{array}$ \\
\hline $\begin{array}{l}\text { Gender } \\
\text { Male } \\
\text { Female }\end{array}$ & $\begin{array}{l}25(62.5) \\
15(37.5) \\
\end{array}$ & $\begin{array}{l}24(60.0) \\
16(40.0) \\
\end{array}$ & $\begin{array}{l}49(61.3) \\
31(38.7) \\
\end{array}$ & $\begin{array}{c}\mathrm{X}^{2}=0.05 \\
p=0.818\end{array}$ \\
\hline $\begin{array}{l}\text { POA (weeks) } \\
28-30 \\
31-33 \\
34-36 \\
37 \text { or }>\end{array}$ & $\begin{array}{l}05(12.5) \\
13(32.5) \\
08(20.0) \\
14(35.0)\end{array}$ & $\begin{array}{l}02(05.0) \\
08(20.0) \\
12(30.0) \\
18(45.0)\end{array}$ & $\begin{array}{l}07(08.8) \\
21(26.3) \\
20(25.0) \\
32(40.0)\end{array}$ & $\begin{array}{l}\mathrm{X}^{2}=3.78, \\
p=0.287\end{array}$ \\
\hline $\begin{array}{l}\text { Birth weight (g) } \\
<1500 \\
1500-2500 \\
>2500\end{array}$ & $\begin{array}{l}10(25.0) \\
16(40.0) \\
14(35.0) \\
\end{array}$ & $\begin{array}{l}09(22.5) \\
11(27.5) \\
20(50.0) \\
\end{array}$ & $\begin{array}{l}19(23.8) \\
27(33.8) \\
34(42.5) \\
\end{array}$ & $\begin{aligned} \mathrm{X}^{2} & =2.037 \\
p & =0.361\end{aligned}$ \\
\hline $\begin{array}{l}\text { Mode of delivery } \\
\text { Normal vaginal } \\
\text { Elective LSCS } \\
\text { Emergency LSCS } \\
\text { Instrumental } \\
\end{array}$ & $\begin{array}{l}03(07.5) \\
05(12.5) \\
31(77.5) \\
01(02.5)\end{array}$ & $\begin{array}{l}08(20.0) \\
10(25.0) \\
21(52.5) \\
01(02.5)\end{array}$ & $\begin{array}{l}11(13.8) \\
15(18.75) \\
52(65.0) \\
02(02.5)\end{array}$ & $\begin{array}{l}\mathrm{X}^{2}=5.86, \\
p=0.118\end{array}$ \\
\hline $\begin{array}{l}\text { Diagnosis } \\
\text { Congenital pneumonia } \\
\text { RDS } \\
\text { Other }\end{array}$ & $\begin{array}{l}06(15.0) \\
29(72.5) \\
05(12.5) \\
\end{array}$ & $\begin{array}{l}06(15.0) \\
23(57.5) \\
11(27.5) \\
\end{array}$ & $\begin{array}{l}12(15.0) \\
52(65.0) \\
16(20.0) \\
\end{array}$ & $\begin{array}{l}X^{2}=2.94, \\
p=0.230\end{array}$ \\
\hline $\begin{array}{l}\text { Maternal risk factors } \\
\text { No Risk } \\
\text { GDM } \\
\text { PIH } \\
\text { Other }\end{array}$ & $\begin{array}{l}16(40.0) \\
04(10.0) \\
14(35.0) \\
03(07.5)\end{array}$ & $\begin{array}{l}23(57.5) \\
03(07.5) \\
03(07.5) \\
08(20.0)\end{array}$ & $\begin{array}{l}39(48.8) \\
07(08.8) \\
17(21.3) \\
11(13.8)\end{array}$ & $\begin{array}{c}\mathrm{X}^{2}=10.79 \\
p=0.013\end{array}$ \\
\hline
\end{tabular}

POA: Period of amenorrhoea, LSCS: lower segment caesarean section, RDS: respiratory distress syndrome, GDM: gestational diabetes mellitus, PIH: pregnancy induced hypertension

Babies born through emergency caesarean section needed more respiratory support than other modes of deliveries. Type of respiratory support did not show any association with period of amenorrhoea (POA), birth weight (BW), mode of delivery (MOD) or cause of 
respiratory distress. Around half the sample $(48.7 \%)$ of neonates who needed respiratory support were babies born to mothers with no risk factors. Among the risk factors, pregnancy induced hypertension $(\mathrm{PIH})$ was the commonest ( $21 \%$ of total sample). Association with maternal risk factors was statistically significant $(p=0.013)$. Effectiveness of CPAP and NIPPV in neonates with mild to moderate respiratory distress is shown in Table 2.

Table 2: Effectiveness of CPAP and NIPPV in neonates with mild to moderate respiratory distress

\begin{tabular}{|c|c|c|}
\hline & \multicolumn{2}{|c|}{ Respiratory support } \\
\hline & NIPPV & CPAP \\
\hline Non-invasive respiratory support failure & $14(35 \%)$ & $16(40 \%)$ \\
\hline Absence of non-invasive respiratory support failure & $26(65 \%)$ & $24(60 \%)$ \\
\hline Total & $\mathbf{4 0 ( 1 0 0 \% )}$ & $\mathbf{4 0}(\mathbf{1 0 0} \%)$ \\
\hline
\end{tabular}

Risk of developing respiratory failure was 1.14 (95\%CI 0.65-2.01) times higher among CPAP than NIPPV but this was not statistically significant $(\mathrm{p}=0.644)$.
Association between type of respiratory support and grades 3 and 4 intraventricular haemorrhage (IVH) is shown in Table 3.

Table 3: Association between type of respiratory support and Grades 3 and 4 IVH

\begin{tabular}{|l|l|c|c|c|}
\hline & & NIPPV & CPAP & Level of significance \\
\hline IVH & Presence & $02(05 \%)$ & $01(2.5 \%)$ & $\mathrm{RR}=2(\mathrm{CI} 0.18-21.18), p=0.56$ \\
& Absence & $38(95 \%)$ & $39(97.5 \%)$ & \\
\hline
\end{tabular}

IVH: intraventricular haemorrhage

There were two neonates with grade $3 / 4 \mathrm{IVH}$ in the NIPPV group and only one neonate in CPAP group. As the number was small, an association could not be calculated using the Chi square test. Data showed twice the risk of developing IVH among NIPPV compared to CPAP but this was not statistically significant
( $p=0.56)$. There was no significant difference in the presence of IVH between the two groups of respiratory support.

Comparison of duration of support and length of hospital stay is shown in Table 4.

Table 4: Comparison of duration of support and length of hospital stay

\begin{tabular}{|l|c|c|c|c|}
\hline & Mean & $\begin{array}{c}\text { Standard } \\
\text { deviation }\end{array}$ & $\begin{array}{c}\text { Mean } \\
\text { difference }\end{array}$ & $\begin{array}{c}\text { Level of } \\
\text { significance }\end{array}$ \\
\hline Duration of respiratory support & 6.23 & 3.919 & 0.825 & $p=0.381$ \\
NIPPV & 5.40 & 4.448 & & \\
CPAP & & & & \\
\hline Duration of hospital stay & 7.23 & 4.312 & 0.550 & $p=0.584$ \\
NIPPV & 6.68 & 4.621 & & \\
CPAP & &
\end{tabular}

Neither duration of respiratory support nor length of hospital stay showed a statistically significant difference among neonates who received NIPPV and CPAP.
Comparison of time taken to achieve full enteral nutrition among neonates receiving NIPPV and CPAP is shown in Table 5.

Table 5: Comparison of time taken to achieve full enteral nutrition

\begin{tabular}{|l|c|c|c|c|}
\hline & $\begin{array}{c}\text { Mean duration of } \\
\text { hospital stay }\end{array}$ & $\begin{array}{c}\text { Standard } \\
\text { deviation }\end{array}$ & $\begin{array}{c}\text { Mean } \\
\text { difference }\end{array}$ & $\begin{array}{c}\text { Level of } \\
\text { significance }\end{array}$ \\
\hline $\begin{array}{l}\text { Time taken to achieve full enteral } \\
\text { nutrition }\end{array}$ & & & & \\
NIPPV & 6.50 & 3.138 & 0.000 & $p=1.00$ \\
CPAP & 6.50 & 4.391 & & \\
\hline
\end{tabular}

Mean duration of hospital stay was similar in both groups. There was no statistically significant difference noted in time taken to achieve full enteral feed.

\section{Discussion}

In this randomised trial, we found reduced need for endotracheal intubation and invasive ventilation overall within the first 72 hours in 
the NIPPV group (35\%) when compared with CPAP (40\%) but this was not statistically significant. This finding could mean that there was actually no difference with the two methods or the effect could have been masked because of sample size and heterogeneity of the sample.

The Cochrane meta-analysis done in 2016 concluded that "Early NIPPV does appear to be superior to NCPAP alone for decreasing respiratory failure and the need for intubation and endotracheal tube ventilation among preterm infants with respiratory distress syndrome"16. Our results not showing a significant difference may also be due to it consisting of all the newborn with respiratory distress due to various pathologies. In future research, we need to specifically target groups such as preterm. The devices used are different in other research when compared to our study.

The incidence of severe IVH is high in the NIPPV group compared to CPAP arm, but due to the very small number $\mathrm{Chi}$ square test cannot be applied to our study. But it showed a relative risk of $2(95 \%$ CI $0.18-21.18)$ which is not statistically significant. Other trials which compared the incidence of severe IVH among non-invasive respiratory support showed no difference in CPAP or NIPPV arm ${ }^{15-19}$.

In our study neither duration of respiratory support nor length of hospital stay showed a statistically significant difference between neonates who received NIPPV and CPAP. Armanian et $\mathrm{al}^{20}$ demonstrated a reduction in duration of hospital stay (22 days in the NIPPV group vs 29 days in the CPAP group) while Ramanathan et $\mathrm{al}^{18}$ demonstrated a reduction in the number of days on oxygen among infants who received NIPPV (29 days vs 38 days). The difference may be due to slow weaning protocol of NIPPV group in our hospital management protocol. Other studies including a meta-analysis did not show a difference in duration of hospital stay ${ }^{11}$.

In this research no statistically significant difference was noted in the time taken to achieve full enteral feed. In both arms the mean duration to achieve full feed was 6.5 days. Previous studies did not show a reduction in necrotizing enterocolitis stage $2^{15-18,20-23}$ or time to achieve full feed $\mathrm{f}^{4,7,24,25}$ greater in one treatment group compared with the other.

Limitations of the study include the small sample size, the impossibility to blind caregivers and the heterogeneity of the pathogenesis in the study cohort. Future researche should focus on the effectiveness, safety and long term outcomes such as long-term survival, chronic lung disease and neurodevelopmental impairment of early NIPPV in comparison to CPAP and should focus not only on surfactant deficiency lung disease but also various other disease conditions.

\section{Conclusions}

In our study, the risks for respiratory failure and the need for ventilation were not statistically significantly different whether using NIPPV or CPAP.

\section{Acknowledgements}

We thank Dr. I.E. Gunaratna (Consultant Community Physician), Anti Filariasis Campaign for statistical analysis and data interpretation, the neonatal staff at SJGH for their support and all the parents who gave consent for the study

\section{References}

1. DK Guha, editors, Jaypee Brothers. NNF Recommended Basic Perinatal-Neonatal Nomenclature. Neonatology- Principles and Practice. 1st ed. New Delhi, 1998: 131-2.

2. J Crowther ANNP Updated by Dr Smith. East Cheshire NHS trust Endotracheal Intubation guide line February 2013 Version 2.03

3. Up to date. Mechanical ventilation in neonates. Version 19.3

4. Khalaf M N, Brodsky N, Hurley J. et al A prospective randomized, controlled trial comparing synchronized nasal intermittent positive pressure ventilation versus nasal continuous positive airway pressure as modes of extubation. Pediatrics 2001; 108: 13-7. https://doi.org/10.1542/peds.108.1.13 PMid: 11433048

5. Santin R, Brodsky N, Bhandari V. A prospective observational pilot study of synchronized nasal intermittent positive pressure ventilation (SNIPPV) as a primary mode of ventilation in infants $\geq 28$ weeks with respiratory distress syndrome. 
Journal of Perinatology 2004: 24: 487-93.

https://doi.org/10.1038/sj.jp.7211131

PMid: 15141265

6. Lin $\mathrm{C} H$, Wang $\mathrm{S} \mathrm{T}$, Lin $\mathrm{Y}$ J. et al Efficacy of nasal intermittent positive pressure ventilation in treating apnoea of prematurity. Pediatric Pulmonology 1998; 26: 349-53.

https://doi.org/10.1002/(SICI)1099-04 96(199811)26:5<349::AID-PPUL8>3 .0.CO;2-7

7. Barrington KJ, Bull D, Finer NN, et al. Randomized trial of nasal synchronized intermittent mandatory ventilation compared with continuous positive airway pressure after extubation of very low birth weight infants.

Pediatrics 2001; 107:4 63841.

https://doi.org/10.1542/peds.107.4.63 8

8. Bhandari V. Nasal intermittent positive pressure ventilation in the newborn: review of literature and evidence-based guidelines. Journal of Perinatology 2010; 30:505.

https://doi.org/10.1038/jp.2010.117

PMid: 19847188

9. De Paoli AG, Davis PG, Lemyre B. Nasal continuous positive airway pressure versus nasal intermittent positive pressure ventilation for preterm neonates: a systematic review and meta-analysis. Acta Paediatrica 2003; 92:70.

https://doi.org/10.1111/j.1651-2227.2

003.tb00472.x

PMid: 12650303

10. Lemyre B, Davis PG, De PaoliAG, KirpalaniH. Nasal intermittent positive pressure ventilation (NIPPV) versus nasal continuous positive airway pressure (NCPAP) for preterm neonates after extubation. Cochrane Database of Systematic Reviews 2017, Issue 2. Art. No.: CD003212. https://doi.org/10.1002/14651858.CD 003212.pub3

PMid: 28146296

11. Meneses J, Bhandari V, Alves JG: Nasal intermittent positive-pressure ventilation vs nasal continuous positive airway pressure for preterm infants with respiratory distress syndrome. a systematic review and meta-analysis. Archives of Pediatric and Adolescent Medicine 2012; 166:372-6.

https://doi.org/10.1001/archpediatrics. 2011.1142

PMid: 22474063

12. Roberts C.T., Davis P.G. Owen L.S. Neonatal Non-Invasive Respiratory Support: Synchronised NIPPV, Non-Synchronised NIPPV or Bi-Level CPAP: What Is the Evidence in 2013? Neonatology Karger publisher. 2013; 104(3): 203-9.

13. Perinatal society of Sri Lanka in collaborating with WHO collaborating centre for training and research in new born care, All India Institute of Medical Science. Work book on neonatal ventilation. Learner's guide April 2008.

14. Claure N, Bancalari E. New modes of mechanical ventilation in the preterm newborn: evidence of benefit. Archives of Disease in Childhood. Fetal and Neonatal Edition 2007; 92:F508.

https://doi.org/10.1136/adc.2006.1088 52

PMid: 17804519 PMCid:

PMC2675409

15. Kugelman I. Feferkorn A. Riskin I. Chistyakov B. Kaufman, D. Bader, et al. Nasal Intermittent Mandatory Ventilation Versus Nasal Continuous Positive Airway Pressure for Respiratory Distress Syndrome: A Randomized, Controlled, Prospective Study. Journal of Pediatrics 2007; 150(5): 521-6.

16. Lemyre B, Laughon M, Bose C, Davis PG. Early nasal intermittent positive pressure ventilation (NIPPV) versus early nasal continuous positive airway pressure (NCPAP) for preterm infants. Cochrane Database of Systematic Reviews 2016, Issue 12. Art. No.: CD005384. 
https://doi.org/10.1002/14651858.CD

005384.pub2

PMid: 27976361

17. Bisceglia M, et al: A comparison of nasal intermittent versus continuous positive pressure delivery for the treatment of moderate respiratory syndrome in preterm neonates. Minerva Pediatrics 2007; 59:91-5.

PMid: 17404558

18. Ramanathan R, Sekar KC, Rasmussen M, Bathia J, Soll RF. Nasal intermittent positive pressure ventilation after surfactant treatment for respiratory distress syndrome in preterm infants under 30 weeks gestation: a randomized controlled trial. Journal of Perinatology 2012; 32(5):336-43.

https://doi.org/10.1038/jp.2012.1

PMid: 22301528

19. Meneses J, et al: Noninvasive ventilation for respiratory distress syndrome: a randomized controlled trial. Pediatrics 2011; 127:300-7. https://doi.org/10.1542/peds.2010-092 2

PMid: 21262883

20. Armanian AM, Badiee Z, Heidari G, Feizi A, Salehimehr N. Initial treatment of respiratory distress syndrome with nasal intermittent mandatory ventilation versus nasal continuous positive airway pressure: a randomized controlled trial. International Journal of Preventive Medicine 2014; 5(12): 1543-51.

PMid: 25709790 PMCid:

PMC4336985

21. Sai Sunil Kishore M, Dutta S, Kumar P: Early nasal intermittent positive pressure ventilation versus continuous positive airway pressure for respiratory distress syndrome. Acta Paediatrica 2009; 98:1412-5. https://doi.org/10.1111/j.1651-2227.2 009.01348.X

PMid: 19523049

22. Wood FE, Gupta S, Tin W, Sinha S. Randomised controlled trial of synchronised intermittent positive airway pressure (SiPAP) versus continuous positive airway pressure (CPAP) as a primary mode of respiratory support in preterm infants with respiratory distress syndrome. Archives of Disease in Childhood 2013; 98(Suppl 1):A1-117. https://doi.org/10.1136/archdischild-2 013-304107.182

23. Lista G, Castoldi F, Fontana P, Daniele I, Cavigioli F, Rossi S, et al. Nasal continuous positive airway pressure (CPAP) versus bi-level nasal CPAP in preterm babies with respiratory distress syndrome: a randomised control trial. Archives of Disease in Childhood. Fetal and Neonatal Edition 2009; 95(2):F85-9. https://doi.org/10.1136/adc.2009.1692 19

PMid: 19948523

24. Friedlich P, Lecart C, Posen R, Ramicone E, Chan L, Ramanathan R. A randomized trial of nasopharyngeal synchronised intermittent mandatory ventilation versus nasopharyngeal continuous positive airway pressure in very low birth weight infants following extubation. Journal of Perinatology 1999; 19(6 Pt 1):413-8. https://doi.org/10.1038/sj.jp.7200205 PMid: 10685270

25. Jasani B, Nanavati R, Kabra N, Rajdeo S, Bhandari V. Comparison of non-synchronized nasal intermittent positive pressure ventilation versus nasal continuous positive airway pressure as post-extubation respiratory support in preterm infants with respiratory distress syndrome: a randomized controlled trial. Journal of Maternal-Fetal \& Neonatal Medicine 2016; 29(10):1546-51 https://doi.org/10.3109/14767058.201 5.1059809 PMid: 26135774 